\title{
ARTIGOS
}

\section{PARTICIPAÇÃO POLÍTICA E JUVENTUDE: DO MAL-ESTAR À RESPONSABILIZAÇÃO FRENTE AODESTINO COMUM}

\author{
Lúcia Rabello de Castro
}

\begin{abstract}
RESUMO
O artigo analisa a relação entre juventude e política no contemporâneo, tendo como foco de discussão o processo de subjetivação política, que implica a construção do pertencimento à coletividade e a responsabilização pela vida em comum. As possibilidades de ação engajada e seu sentido político são discutidos frente às aparentes inércia e apatia dos jovens de hoje em relação à política. Um estudo empírico qualitativo com cerca de 25 jovens é apresentado, baseado em entrevistas realizadas tanto com jovens militantes de organizações estudantis e partidos políticos como com aqueles que se engajam no trabalho social voluntário. Na análise, evidenciam-se convergências e divergências entre os dois grupos nos sentidos e objetivos da ação engajada e das formas convencionais de militância. Discutem-se as relações entre as trajetórias desses jovens e o abraçamento de determinadas "causas" que os mobilizam para a ação e a participação na sociedade. Os dois grupos relatam impasses e dificuldades inerentes às escolhas de seus modos de agir e participar: seja por força de buscarem uma eficácia da ação e evitar seus percalços ao submetê-la ao enquadramento da política institucionalizada; seja por força das concessões que se vêem fazendo aos princípios e ideais partidários, distanciando a ação de seu fundamento. Tais dificuldades remetem à distinção entre a política e o político, tendo em vista que a forma institucionalizada de fazer política hoje parece não dar mais conta das demandas da vida em comum; por outro lado, as novas formas de participação política podem insular-se nas ações pontuais. Conclui-se que, para os jovens entrevistados, as formas de participação e de engajamento social enveredam por caminhos diversos, sejam os da política institucional, sejam os da ação militante no trabalho social voluntário; embora o sentido político das ações nem sempre seja explicitamente admitido, as formas convencionais da ação política permanecem em tensão com outras escolhas de engajamento e de participação na sociedade.
\end{abstract}

PALAVRAS-CHAVE: juventude; subjetivação política; participação; coletivo; democracia; vínculos sociais.

\section{INTRODUÇÃO}

A participação política dos jovens não se faz no vazio cultural e histórico, mas em sociedades reais que carregam as marcas singulares de sua história e as dificuldades específicas de seu presente. No contexto das desigualdades sociais da sociedade brasileira, compreender como e porquê os jovens brasileiros participam da construção e da decisão societárias põe em questão a forma como cada um reconhece-se como integrante desse conjunto tão desigual e como se vê implicado nos seus destinos. Assim, a participação política não pode desvincular-se das condições subjetivantes que darão forma ao sentimento de pertencimento à coletividade por parte de jovens e de crianças e de como essa coletividade é representada por eles.

A lenta assunção de cada indivíduo à condição de sentir-se, de reconhecer-se e de agir como parte desse todo maior apóia-se na construção dos laços sociais, derivados não da semelhança entre iguais, nem tampouco das afinidades de parentesco ou afetivas, mas da identificação com objetivos considerados coletivamente como importantes. Para o jovem, "sair de casa", no sentido de assumir-se como integrante da polis ou da nação, significa entender-se como "tendo a ver" com o estado de coisas ao seu redor e interpelado a responsabilizar-se por elas. Pertencimento e responsabilização imbricam-se e constituem aspectos subjetivos primordiais no processo de assumir-se como membro de uma sociedade, seja ela qual for. Nesse processo, uma dupla passagem é necessária: uma que se dá por meio de novas identificações com objetivos coletivamente gerados (MOUFFE, 1993), outra que se realiza por meio do engajamento concreto do indivíduo em ações e movimentos com os outros, propiciando novas determinações e fluxos dentro da sociedade. 
Neste trabalho pretendemos discutir alguns caminhos e vias pelos quais os jovens brasileiros constroem tais pertencimento e responsabilização frente ao destino comum, inaugurando possibilidades de participação política. Não consideramos que essa participação deva ser necessariamente entendida como uma contribuição marginal ou tentativa, seja como uma simulação, seja como uma aprendizagem à ulterior participação política "real”, como muitos autores fazem quando se referem ao processo de "socialização política" (FLANAGAN \& SHERROD, 1998, p. 448). Consideramos que o processo de construção da subjetividade política (RANCIÈRE, 1995) diz respeito a todas as experiências de comparecimento e de adesão dos jovens a um espaço de disputas em torno do que vai mal no seu entorno e na sociedade em geral, que os leva, conseqüentemente, a assumir ações junto com outros em prol da igualdade, da justiça e da emancipação.

Dessa forma, as experiências de participação política podem ser "reais" ao longo da infância e da adolescência, na medida em que esses sujeitos participam de situações de construção de espaços comuns de negociação e de luta. O voto aos 18 ou aos 16 anos por si só, não garante, de modo algum, um comprometimento maior com as lutas de transformação social; alguns autores observam mesmo um declínio desse tipo de participação nas sociedades ocidentais contemporâneas, não apenas em relação aos jovens, mas em relação a todos os outros segmentos etários (FORBRIG, 2005, p. 11). Nesse sentido, desejamos discutir a participação como uma demanda subjetiva, isto é, como o reposicionamento que os indivíduos fazem frente à sociedade mais ampla, expresso pela maneira como cada um busca vincular-se à coletividade e lançar-se em espaços de discurso e de ação no intuito de afirmarem-se como seus membros. Nessa perspectiva, pretendemos questionar a noção de "participação política”, entendida apenas como ação engajada por meio dos mecanismos instituídos de pressão e reivindicação. Esses mecanismos, estabelecidos nas formas de representação política de partidos e agremiações parapolíticas (organizações estudantis, sindicatos etc.), reiteram a maneira conhecida e legitimada de "fazer-se política", interpelando os jovens a tomarem uma posição de luta tendo em vista idéias de transformação do país. No entanto, juntamente com outros autores (ION, 1996; CELLIER, 2004;GRIFFIN, 2005; KOVACHEVA, 2005), en- tendemos que a responsabilização frente ao destino comum vai além da militância nas organizações partidárias e parapartidárias. Ainda que essa militância seja imbuída de uma perspectiva totalizante da sociedade e permita ao jovem aprender a lidar com a pluralidade de interesses que compõem a vida em comum, surgem hoje novas possibilidades de luta pela transformação do presente, que põem em curso demandas de transformação social a partir de rupturas de "baixo para cima”, implodindo fronteiras e identidades e deslocando a noção do político para as margens do que é convencionalmente concebido como tal. A questão da participação dos jovens abre novos horizontes para compreender como em cada contexto histórico e cultural a própria política (entendida como a forma de refundar a convivência social) pode ser reinventada.

\section{SUBJETIVAÇÃO POLÍTICA E JUVENTUDE NO CONTEMPORÂNEO}

Entender a si mesmo como parte de um todo maior - uma nação por exemplo - requer uma lenta transformação subjetiva que redimensiona o sentido de lugar e de inserção do jovem. Se a casa dos pais foi, e continuará sendo, uma referência importante para responder às perguntas "quem eu sou?" "de onde vim?”, outras questões impõemse gradualmente e que dizem respeito aos vínculos mais amplos com todos os outros com quem compartilha os mesmos valores, costumes, língua e sensibilidades.

A vida na cidade - em grandes cidades brasileiras, como Rio de Janeiro, São Paulo e outras tantas, no Brasil e no mundo - é uma experiência importante e intensa de mobilização da questão do outro: "quem são, de onde vêm, o que significam todos esses outros - estranhos - com quem se divide o território, as experiências de circulação e de lazer e de quem se depende para realizar objetivos próprios de estudo ou trabalho?”. A vida urbana expõe os jovens à experiência radical de confronto com um "outro" diferente dos pais e dos familiares, convocando-os a compreender e dar conta de vínculos que os unem, ou não, a esses outros - diferentes, estranhos, próximos e distantes ao mesmo tempo. Como vários autores apontam, a experiência urbana contemporânea favorece a visão das diferenças (LEFEBVRE, 1974; NEGT, 2002) e das desigualdades (SANTOS \& SILVEIRA, 2001) no horizonte das lutas pela igualdade (DOMINGUES, 2000). Esse processo é lo- 
calizado histórica e culturalmente, o que significa que construir a dimensão do vínculo social que dá conta da inserção no todo mais amplo está submetido às condições específicas de história e de cultura que estruturam a experiência subjetiva.

Certamente, hoje, no Brasil como em outros países, a cultura do consumo globalizada conduz todos, inclusivamente os jovens, a uma privatização crescente da experiência, em que o importante é a fruição de prazeres ditos "privados”, como as emoções intensas relacionadas a experiências corporais e estéticas orientadas por valores como o bem-estar e a felicidade individuais, a segurança e o conforto (ARENDT, 1972; SENNETT, 1992). Contrariamente a isso, o processo de subjetivação política pauta-se por experiências que levam os jovens a interrogarem-se sobre o que está inadequado e difícil na convivência humana ao seu redor. Dessa forma, esse processo coloca o jovem frente às contradições de sua época e no encalço de outros que possam ajudá-lo a responder tais questões e a agir frente a elas.

Para o jovem brasileiro, a interpelação para um outro tipo de pertencimento à coletividade, diferente daquele do lar e da família, esbarra em um cenário singular. A sociedade brasileira, conforme ela apresenta-se hoje nas suas formas mais visíveis do espaço urbano, expõe o fosso abismal entre as elites e o enorme contingente de pobres e miseráveis. País que carrega uma herança cultural de quase 400 anos de escravidão dos negros e um processo de modernização que acumulou uma dívida social cujas cifras são assustadoras, o Brasil não conseguiu implantar práticas sociais fundadas sobre direitos universais reais e não apenas de jure - a liberdade e a igualdade para todos. Se os direitos universais - à educação, por exemplo - não têm sido de facto implementados, principalmente para crianças e jovens pobres ${ }^{1}$ (ainda que as leis brasileiras preconizem-nos), a situação de fato parece demasiadamente real nos seus efeitos de subjetivação, ou seja, corre-se o risco de naturalizar-se o arbítrio humano, de habituar-se com as desigualdades e com o mal-estar que elas causam. Com efeito, alguns autores (por ex., CARVALHO, 2002) comentam esses efeitos subjeti-

${ }^{1}$ De acordo com o IBGE (2003), dos aproximadamente 50 milhões de jovens brasileiros entre 10 e 24 anos, $7 \%$ entre 10 e 14, 30\% entre 15 e 17 e 51\% entre 18 e 19 anos, já estão fora do sistema educacional. vos perversos no coração e na cabeça de muitos brasileiros quando afirmam que em nosso imaginário vigora a máxima da constituição da fábula Animal Farm² de George Orwell: “Todos os animais são iguais, mas alguns animais são mais iguais do que os outros".

Portanto, são muitas as dificuldades que se interpõem na construção dessa passagem dos jovens à sociedade mais ampla, como membros responsáveis pela coletividade. Dar-se conta de que os outros desconhecidos têm a ver consigo ou de como se está vinculado a todos aqueles quem, inicialmente, não se tem nem como parentes nem como amigos, significa reordenar internamente prioridades para que novos investimentos afetivos sejam possíveis, dando lugar a uma nova práxis. Dentro desse cenário, que apresenta dificuldades bastante específicas para o florescimento de uma cultura cívica no Brasil, pode-se perguntar como seria para os jovens a construção de um sentido de pertencimento e de responsabilização, uma vez interpelados a responder o que os liga a todos os outros, os estranhos, com quem convivem na cidade e no país.

A discussão que hoje se faz sobre a participação social e política dos jovens toma importância fundamental na pesquisa científica quando parecem existir indicações de que os jovens não se interessam pela política (WELTI, 2002; PLEYERS, 2005), alimentando ansiedades sobre os efeitos de tal desinteresse sobre a coesão social e o futuro da democracia. O declínio observado por alguns autores em relação aos comportamentos políticos institucionalizados (INGLEHART, 1997) - o voto, por exemplo relaciona-se com mudanças dos valores, quando hoje as novas gerações não se identificam mais com organizações hierarquizadas e burocratizadas e preferem experiências políticas não-convencionais, "expressivas" e informais. Por outro lado, Stolle e Hooghe (2004) complementam essa visão ao alertarem para o fato de que se devem buscar explicações tanto relativas à estrutura (aspectos institucionais e culturais) quanto à agência (aspectos subjetivos). Isso significa que o declínio no interesse dos jovens pela política não é apenas devido à sua falta de motivação pela coisa pública, mas que também pode ser determinado pelo fato de que os recursos para a mobilização e a

2 Conhecida no Brasil como A revolução dos bichos (nota do revisor). 
participação que antes existiam não estão mais disponíveis. Esses autores citam, por exemplo, o fato de que os partidos políticos estão ficando cada vez mais profissionalizados e, portanto, menos propensos a fazer esforços no sentido de aliciar o ingresso maciço de membros, jovens ou velhos.

Assim, muitos aspectos tornam-se relevantes para avaliar a situação dos jovens frente à participação política, mesmo aqueles relativos ao entendimento do que seria participar e do que se entende por política. A própria definição dos pesquisadores sobre o que é a política deveria fazer sentido para os jovens que são por eles pesquisados (KOVACHEVA, 2005), uma vez que os resultados dessas pesquisas orientam políticas públicas para a juventude e canalizam investimentos públicos nessa direção.

No Brasil, poucos estudos examinam a questão da participação política e social dos jovens. Recentemente, o estudo amplo sobre o perfil da juventude financiado pelo Instituto da Cidadania (ABRAMO \& BRANCO, 2005) mostrou algumas relações entre política e juventude. Ressaltam-se alguns aspectos: apenas 15\% de jovens participam de quaisquer atividades de grupo no bairro e na cidade, mesmo que 37\% dos jovens reconheçam que a política "influi muito" em suas vidas. Além disso, o item "confiança nas instituições" mostra que $83 \%$ dos jovens confiam totalmente na família, mas, no que se refere aos partidos políticos, esse valor é de apenas 3\% (ABRAMO \& BRANCO, 2005). Em outro estudo com 8000 jovens de todo o Brasil, conduzido pelo Instituto Polis e pelo Instituto Brasileiro de Análises Sociais e Econômicas (Ibase) (POLIS-IBASE, 2006), os resultados indicam que apenas $8,5 \%$ dos jovens consideravam-se politicamente participantes, embora $65,6 \%$ tenham afirmado buscar informações sobre política, mas sem participar diretamente. A grande maioria dos jovens dessa pesquisa (65\%) mostrou descrença em relação à representatividade dos políticos na defesa dos interesses dos cidadãos e enfatizaram a corrupção, a desorganização e a fragmentação de projetos que não geram resultados. Afirmaram ainda a importância das ações voluntárias e comunitárias como forma de participação que lhes é mais acessível (idem). Por meio desses dois estudos, é possível constatar que uma compreensão maior das relações entre política e juventude hoje exige, sobretudo, que se possam ouvir os jovens, tanto nas suas críticas em relação ao modo vigente de fazer-se política, quanto nos encaminhamentos que podem fazer, e efetivamente fazem, em relação às novas possibilidades do jogo democrático.

\section{A PARTICIPAÇÃO POLÍTICA DE JOVENS NO CONTEMPORÂNEO}

Passamos a apresentar os resultados de uma pesquisa qualitativa sobre a participação política de jovens por meio da análise de entrevistas realizadas $^{3}$ com 25 sujeitos inseridos seja no trabalho social voluntário, seja em organizações partidárias e/ou estudantis no estado do Rio de Janeiro. Buscou-se compreender as condições que estruturam o ingresso dos jovens em tais movimentos e organizações, além das conseqüências das escolhas de inserirem-se e participarem na sociedade a partir de uma outra posição.

Para fins da análise, o grupo foi dividido em dois: um composto por aqueles que tinham filiação partidária ou militavam em organizações estudantis; o outro composto por aqueles engajados no trabalho social e comunitário voluntário. Essa divisão pôde identificar aspectos importantes referentes ao laço social nos dois grupos, assim como convergências e diferenças na forma de encararem sua adesão à causa comum e os efeitos de sua ação. A escolha desses grupos não se deve ao fato de eles representarem posições claramente excludentes e/ou antagônicas, já que, por exemplo, muitos jovens que militam nas organizações partidárias iniciaram sua vida de militância no trabalho social voluntário, mas, em função do que se objetiva aqui - a compreensão da natureza dos vínculos que os jovens endereçam à sociedade mais ampla -, esses grupos constituem lugares diferentes que permitem percepções e ações distintas por parte dos jovens em relação a como e porquê abraçar uma "causa". Nesse sentido, tais grupos estimulam determinadas ações e percepções de si mais do que outras e favorecem determinados sentidos da ação coletiva em detrimento de outros, como veremos a seguir.

As idades dos jovens variaram entre 16 a 28 anos, segundo o Quadro 1, que também apresenta suas filiações institucionais.

\footnotetext{
3 Projeto de pesquisa intitulado "Diferença e participação: subjetivação política na infância e na adolescência”, apoiado pelo Conselho Nacional de Desenvolvimento Científico e Tecnológico (CNPQ) e pela Fundação Carlos Chagas de Amparo à Pesquisa do Estado do Rio de Janeiro
} (Faperj). 
QUADRO 1 - JOVENS ENTREVISTADOS: FILIAÇÃO INSTITUCIONAL, IDADE E GÊNERO

\begin{tabular}{|c|c|c|}
\hline $\begin{array}{l}\text { PARTIDOS } \\
\text { POLÍTICOS }\end{array}$ & $\begin{array}{l}\text { ASSOCIAÇÕES ESTUDANTIS, } \\
\text { MOVIMENTOS SOCIAIS, ONGS }\end{array}$ & GRÊMIOS \\
\hline $\begin{array}{l}\text { F., PDT, } 17 \text { a., M. } \\
\text { R., PSOL, } 21 \text { a., M. } \\
\text { D., DEM, } 24 \text { a., M. } \\
\text { S., PSDB, } 24 \text { a., M. } \\
\text { R., PSDB, } 28 \text { a., M. } \\
\text { I., PSDB, } 18 \text { a., F. } \\
\text { F., PT, } 23 \text { a., F. } \\
\text { A., PV, } 19 \text { a., F. }\end{array}$ & $\begin{array}{l}\text { G., Colégio D. Pedro II, } 17 \text { a., M. } \\
\text { A., Escola Anísio Teixeira, } 17 \text { a., M. } \\
\text { N., Escola Abel, } 16 \text { a., F. } \\
\text { M., Cefet-RJ, } 16 \text { a., F. } \\
\text { P., Escola São Vicente, } 17 \text { a., M. } \\
\text { J., DCE-UFRJ, } 21 \text { a., F. } \\
\text { C., UERJ, } 20 \text { a., F. } \\
\text { R., UFF, } 23 \text { a., M. } \\
\text { D., DCE-USU, } 20 \text { a., F. } \\
\text { P., UBES, } 23 \text { a., M. } \\
\text { R., UEE, } 21 \text { a., M. } \\
\text { A., AMES, } 19 \text { a., M. }\end{array}$ & $\begin{array}{l}\text { F., Radio Comunitário Mme. Satã, } 23 \text { a., M. } \\
\text { M.,Movimento Afro-Reggae, } 19 \text { a., M. } \\
\text { T., Centre de Cultura Afro, } 17 \text { a., M. } \\
\text { E., Movimento Capoeira, } 23 \text { a., M. } \\
\text { M., ONG Consciência Cidadã, } 21 \text { a., M. } \\
\text { T., ONG Alma, } 22 \text { a., F. } \\
\text { P., ONG Lumina, } 19 \text { a., M. } \\
\text { F., ONG Vetor, } 23 \text { a., M. } \\
\text { M., Missão Infância, } 18 \text { a., F. } \\
\text { R., Movimento Brasil, } 25 \text { a., M. }\end{array}$ \\
\hline
\end{tabular}

FONTE: a autora.

NOTA: PDT: Partido Democrático Trabalhista; PSOL: Partido Solidariedade e Liberdade; DEM: Partido Democratas; PSDB: Partido da Social-Democracia Brasileira; PT: Partido dos Trabalhadores; PV: Partido Verde; Cefet-RJ: Centro Federal de Ensino Tecnológico do Rio de Janeiro; DCE: Diretório Central dos Estudantes; UFRJ: Universidade Federal do Rio de Janeiro; UERJ: Universidade Estadual do Rio de Janeiro; UFF: Universidade Federal Fluminense; PSU: Universidade Santa Úrsula; UBES: União Brasileira de Estudantes Secundaristas; UEE: União Estadual de Estudantes do Rio de Janeiro; AMES: Associação Metropolitana de Estudantes Secundaristas; ONG: organização não-governamental.

III.1. A militância juvenil nos partidos políticos e nos movimentos estudantis: a política como visão crítica da sociedade e a participação em prol de sua ampla transformação

A adesão de jovens à causa político-partidária está relacionada ao desejo de transformação social e à expectativa de um mundo melhor, mais justo, com menos desigualdades sociais, em que "as coisas possam estar menos erradas”. A militância nos partidos é construída lentamente na trajetória de cada jovem, dando continuidade a uma história pessoal de preocupação com a realidade social. Muitos jovens entrevistados, que estavam no momento da entrevista militando em partidos ou nos movimentos estudantis, já participaram como voluntários em serviços a populações pobres (por exemplo, cursos noturnos para jovens carentes que querem entrar na universidade, distribuição de "sopão" para a população de rua, aulas de apoio e recreação para crianças pobres, implantação de tevês comunitárias). Assim, muitas vezes, a causa partidária segue à causa humanitária anteriormente abraçada, mas o ingresso nos partidos ou nos movimentos estudantis assinala uma ruptura no modo de vincular-se à realidade social mais ampla. Alguns jovens ingressaram nos partidos tendo já participado ativamente dos grêmios e dos movimentos estudantis, tendo iniciado na escola seus embates por mudanças. Nesse caso, a participação ativa na vida escolar constituiu um fator importante na história pessoal que favoreceu seu ingresso nos partidos políticos, dando continuidade ao desejo de lutar por mudanças, agora na sociedade mais ampla.

O cerne da motivação para o ingresso no partido, como forma preferencial de militância, consistiu na possibilidade de intervir mais diretamente na sociedade, assegurando uma amplitude maior de ação que aquela desenvolvida por meio de um trabalho social. Nas falas abaixo, de três jovens, dois ligados a partidos e um ao movimento estudantil, constatamos a importância que o programa e a institucionalidade partidárias adquirem na visão dos jovens para que as mudanças possam efetivamente acontecer. "A gente escolheu a via institucional. E pra você intervir na sociedade, você tem que se eleger, entendeu? [...] Porque você pode fazer pressão pra que o governo faça alguma coisa, tipo, os sindicatos são assim [...]. Mas quando você está no governo você pode fazer muito mais, porque você tem a máquina do governo na mão” (F. - PT). "[...] Se você tem, numa sociedade, uma ação correndo prum lado, uma ação correndo pro outro, você não otimiza isso, você gasta dinheiro desnecessariamente... Deve-se sempre buscar uma ação, um programa 
de ação, da Prefeitura, do estado, da União [...]. Porque já existindo uma linha de ação, você não duplica um trabalho gastando dinheiro à toa, gastando recursos [...]” (D. - DEM). “[...] Porém, [...] acredito é [n]o seguinte: você não precisa estar filiado a um partido, mas você precisa ter uma concepção de mundo para entender o seguinte - não adianta você somente militar naquilo ali, naquela causa específica, quando a questão também está ligada a coisas maiores [...]” (P. - UBES).

Assim, a aposta na mudança social para os jovens militantes em partidos e em organizações estudantis assume, quase sempre, um viés programático ligado à linha de ação partidária. Ele é expresso por meio da defesa de um projeto de nação - "coisas maiores" - que explicariam os aspectos menores do cotidiano. Tais idéias programáticas variam segundo o espectro político-partidário: no espectro político mais à direita, os jovens defenderam a "eficiência administrativa” e o "bom uso dos recursos públicos" ou "a análise técnica para basear as decisões políticas”, assim como a promoção de igualdade de oportunidades para todos (jovens filiados ao DEM e ao PSDB); aqueles mais à esquerda enfatizaram as idéias de justiça social e de combater a concentração de riqueza no país (jovens filiados ao PT, ao Partido Comunista do Brasil (PCdoB) e ao PSOL).

Os dois aspectos que foram apontados como fundamentais para a adesão à causa partidária ou à estudantil foram o desejo de transformação social e o de participar ativamente dessa transformação. Quase todos os entrevistados apontaram que um estado de coisas errado convocou-os a uma resposta no sentido de tomar uma atitude. Alguns afirmaram que se dar conta de que alguma coisa vai mal e não fazer nada seria "hipocrisia”. Portanto, o reposicionamento subjetivo de vinculação ao social mais amplo implicou abraçar uma "causa de transformação social" frente ao que vai mal. Tal visão teve o peso de uma convocação para o agir, como explicitada na afirmação que se segue: "Eu faço movimento estudantil porque eu acredito que posso transformar as coisas que estão postas pra mim. A gente vê vários problemas na universidade, vários problemas no nosso curso, a gente vê vários problemas na nossa cidade, vê vários problemas no nosso país, e eu faço movimento estudantil porque eu quero transformar esses problemas” (R. - UFF).
Juntamente com a convocação para o agir, aparecem também a "conscientização" e a necessidade de "compreensão do mundo à sua volta" como expressões freqüentes, ao analisarem sua inserção na militância: "Acho que a vontade de entender muito das coisas que acontecem no Brasil hoje, porque todas dependem da política. O preço da passagem que eu pago [no] ônibus depende da política, o preço do feijão que eu compro no mercado depende da política. Então é a vontade de entender [...] o porquê da evasão dos alunos do Ensino Técnico. Há uma diferença social muito grande. Você não consegue entender porque aquele cara tá num sinal pedindo dinheiro e o outro tá morando numa cobertura" (M. Cefet-RJ).

É interessante notar que, entre os jovens com distintas filiações partidárias, não há uma oposição ideológica notável: todos convergem para princípios gerais como "melhorar os serviços públicos", "combater a corrupção", "dar melhor educação às crianças e aos jovens”. Não se pôde observar um contraste marcante de idéias entre o jovem de um partido socialdemocrata e o jovem do Partido Comunista. No entanto, a crítica feita aos outros partidos surgiu com freqüência nas falas, indicando, assim, uma forma de definir fronteiras ideológicas e de delinear as identidades políticas. Os filiados aos partidos à direita no espectro político criticaram "o blablablá dos da esquerda, que só sabem discutir e não fazem nada” e a "máscara do governo da esquerda que caiu, porque era revolucionário e agora está mostrando ao que veio, com tanta corrupção e não fez nada do que prometeu". Os à esquerda criticaram "o neoliberalismo" dos outros partidos, como uma noção invocada para definir "o grande mal”, sem realmente se deterem sobre quais as propostas neoliberais que devem ser combatidas e porquê; defenderam ainda a idéia de ética na política como princípio de que os fins não devem justificar os meios.

Se um conjunto claro de idéias não parece colocar os jovens em posições distintas ou antagônicas no quadro partidário, quando perguntados sobre como viam sua própria inserção ao longo do espectro político, definido pelas noções de "direita”, “esquerda”, “capitalismo”, "socialismo" e “comunismo”, essas noções também não foram de grande valia para definir sua identidade políti- 
ca: “É, tenho uma orientação política de esquerda. Mas não é aquela esquerda rigorosa, radical, que a gente tem que chegar ao poder, fazer uma revolução armada, por meio da luta, da força. Nós não pregamos isso, somos de esquerda, uma esquerda mais tranqüila [...]. Uma esquerda que visa à reforma” (A. - AMES). "Olha, eu sou uma mistura [risos]. Não, é sério, eu tenho tendências socialistas, mas não sou socialista. Não acredito só no socialismo e não acredito que seja melhor hoje, mas tem muita coisa do socialismo que particularmente eu defendo. Eu particularmente poderia dizer que sou progressista, ponto, mas tem muita coisa no socialismo que eu ainda defendo" (M. - Cefet-RJ). "Nós poderíamos dizer que o PDT é um partido de esquerda, mas na última eleição municipal eu diria que ele foi um partido de direita, porque nosso Prefeito vinha de uma linhagem de partido de direita que acabou se filiando ao PDT. Então, o partido toma uma espécie de forma mais à direita. É [...], o poder transforma um pouco essa coisa de esquerda e direita, porque quem tem o poder não é tão radical [...]" (F. - PDT).

"Ser de esquerda” aparece como uma configuração identitária que compreende um espectro ideológico amplo e, de algum modo, bastante impreciso, como nas definições abaixo: “Ah, eu me acho uma pessoa de esquerda, apesar de que, comparada com outras pessoas que se dizem de esquerda, eu sou totalmente conservadora. Às vezes, eu converso com algumas pessoas do movimento estudantil, que pregam - sei lá! Isso de nacionalizar todas as universidades privadas, sabe? Essas coisas - então, eu me acho conservadora, né? Mas eu acredito que sou de esquerda, uma esquerda sensata - mas de esquerda” (J. UFRJ). "Mas eu me considero de esquerda por acreditar numa sociedade mais justa e, de maneira geral, é isso que caracteriza todo esse campo. $\mathrm{E}$ aí a direita, eles querem conservar as coisas como estão, o centro seriam aqueles envergonhados que não sabem onde estão e topam tudo do jeito que está; a esquerda seriam aqueles que querem mudar, mas [sobre] essa mudança, aí tem todo um debate [...]” (R. - UEE).

Desse modo, a taxionomia política convencional parece não servir para estabelecer fronteiras claras nas identidades políticas entre os jovens, seja porque, para eles, ela não estabelece conjuntos díspares de ideais e causas, seja porque, na prática, as lutas podem ser encampadas por um ou outro campo político forçando convergências. O que importa assinalar aqui é que as identificações políticas com determinados campos partidários fazem-se, para os jovens, para além das convenções usualmente reconhecidas para definir campos políticos opostos.

Nesse sentido, os jovens entrevistados afirmaram a importância da filiação partidária, seja ela qual for: há um efeito narcísico poderoso ao sentirem-se reconhecidos pelos outros como líderes, como fazendo um trabalho relevante para a sociedade, como efetivando mudanças visíveis na escola, na universidade ou na comunidade. Algo ocorre na militância que os fazem sentir-se potentes e capazes: "E aí, o que acontece? Como seus amigos não passam por esse processo que você está passando, ou você tenta que eles pelo menos compreendam que a política é importante, que eles têm que ler o jornal, que eles têm que entender política, que eles têm que ler o jornal para entender o que está acontecendo no país; saber quem é o fulano, o beltrano, saber se pode confiar em fulano, saber as movimentações políticas que estão por detrás de qualquer coisa. Ou você tenta conquistar a mente e o coração do seu amigo ou você vai ter que ter momentos de alienação, porque, senão, você perde seus amigos. Ou você se enquadra no mundo deles” (F. - PT). [...] De aglutinar poderes, de aglutinar forças para fazer uma transformação real e profunda, que a gente vê todos os dias, problemas sociais, problemas estruturais mesmo na sociedade; esses movimentos sociais, principalmente os partidários, são formas de você estar ajudando a transformar o que você acha errado" (N. - Abel).

Militar no movimento estudantil ou no partido confere aos jovens reconhecimento social e pertencimento. Tornar-se membro de um organismo (partido ou associação estudantil), que é considerado por eles mesmos como "forte" e visível, permite-lhes verem-se de um novo lugar que confere importância e outro significado às suas ações. Dessa forma, os jovens podem exorcizar o limbo a que são condenados na longa moratória da adolescência em que todos são apenas estudantes, ou seja, indivíduos que se preparam para um futuro profissional. A fala desses jovens, ao enfatizarem suas possibilidades de ação no presente e a relevância do que estão fazendo, conferida pelo pertencimento a um partido ou a 
uma associação, leva-nos a crer que os espaços de luta e de discussão política constituem um referencial importante para a formação de identidades juvenis, para além daquelas comumente consideradas, como a família e a escola.

"Sair de casa" como metáfora da busca de vínculos sociais mais amplos significa em geral, para os jovens, um adiamento da identidade e da ação que somente virão mais tarde pelo delineamento profissional. Isso pode ser sentido de maneira negativa como um amordaçamento a que estão submetidos que os rechaça para as bordas da sociedade, impedindo sua ação. A ação militante dos jovens traz para o presente o agir e as gratificações que dele decorrem, como exemplificadas nas falas dos jovens abaixo: "Tem certos tipos de coisas que te fazem legal, eu estar aqui porque participei de um processo da história. Por exemplo, a questão do passe livre em 1999 foi uma parada e assim que... pô! A gente colocou 5000 alunos nas ruas e gente luta até hoje pelo passe livre” (F. - PT). “A UBES sempre esteve ligada às questões mais gerais do Brasil. Você pega qualquer coisa nos últimos 50 anos, que sejam acontecimentos importantes na vida política do país, a UBES estava presente [...]. Estava presente na eleição de Lula, na época do ‘fora Collor' foi quem mais mobilizou os jovens. Então a luta da UBES se confunde com a história política do país” (P. UBES). "O que a gente percebeu é que existem outras três deficiências que o Estado não atende: uma delas é a educação, a segunda é a falta de trabalho e a terceira é a fome. Eu considero que o meu trabalho em educação já foi resolvido. Quais são os outros dois paradigmas que eu tenho que resolver hoje? É o da fome e o do primeiro emprego. O da fome eu já resolvo, estou trabalhando hoje num projeto chamado Projeto Oásis, que distribui sopa na rua para pessoas... Agora, esse trabalho que estamos montando, que é o do primeiro emprego, que ainda não decolou, estamos juntando a equipe, esse tipo de coisa” (R. - PSDB).

Foi interessante observar em todos os depoimentos que o vínculo intenso com as causas de transformação social faz que renunciem ao amor (muitos desentendem-se com seus namorados), são criticados e mal interpretados pela família, passam agruras financeiras e são reprovados nos estudos. Os inúmeros conflitos entre a vida pessoal e o investimento nas causas são decorrentes de sua opção pela atividade militante, que, para os entrevistados, é alguma coisa da qual não podem abrir mão. Dessa forma, pertencer a um partido ou a uma organização estudantil garante-lhes uma autorização para agir, permitindo um sentimento de eficácia subjetiva por meio de sua contribuição social e política no presente, reforçando o sentido de pertencimento a um todo maior: "Tem gente na UJS [União da Juventude Socialista] que não passou no vestibular por causa da UJS, tem gente que foi proibido pela mãe de ir à UJS porque estava atrapalhando muito, entendeu? Eu nem sou um dos que participa mais, tem gente [para] que[m] a UJS é prioridade absoluta, só vive pela UJS, só fazem ir para a UJS...” (P. - Esc. S. Vicente).

Nesse sentido, o que parece importante ressaltar aqui é como cada um desses jovens lida cotidianamente com o conflito entre a busca da felicidade e a da sobrevivência e a adesão à causa coletiva, uma vez que parecem ser projetos que os arrastam a direções opostas. Esse é um ponto que merece destaque, pois alude às questões amplamente discutidas sobre a crescente retração dos indivíduos para a vida privada (ARENDT,1963; BECK, 1998), o declínio do interesse pelo que é comum (SENNETT, 1992) e a transformação dos atores sociais em clientes que delegam ao poder representativo a tarefa de decidir sobre o destino comum (VILLA, 1992). Para os jovens dessa pesquisa, embora a opção pela causa coletiva causelhes dificuldades, ela permanece como fundamental nas suas vidas. Não se sabe, porém, até quando "resistirão", já que também assinalam a dureza dos conflitos resultantes de abrir mão dos projetos pessoais em prol da adesão à causa coletiva.

Se o projeto coletivo pode ser, às vezes, difícil, há um sentido de excepcionalidade que os militantes concedem-se por serem membros de uma organização mais ampla, em que a situação indefinida de qualquer jovem adolescente é ressignificada: os jovens que militam nos partidos e nas associações estudantis sentem-se diferenciados dos outros, considerados como “despolitizados”, "alienados”, “individualistas”, “entreguistas” e "com aversão à política”. A maior crítica dos militantes é dirigida aos jovens que têm dinheiro e deixam-se absorver pelo consumo e em si mesmos, mas também se dirige ao modo como hoje se vive a vida, todos absorvidos na luta pela sobrevivência. A militância confere o sentimento de estarem enxergando "para além do horizonte" da maioria dos mortais e a responsabilidade de poder "representar" outros jovens. A fala da jovem abaixo retrata tal situação: "Sabe, se eu 
mudar a cabeça de um jovem, pra mim eu já fico feliz. Que eu consiga pegar uma 'patricinha' sabe? Que só pensa em ir pro shopping - e mostrar pra ela que é importante assistir [a]o horário político, por exemplo, eu vou estar muito feliz" (M. - Cefet-RJ).

Entre os que militam nos diferentes partidos e nos movimentos estudantis não há convergência sobre quais as causas dos jovens são mais importantes: há menção de lutas pontuais como o passe livre, a reforma universitária e o primeiro emprego. Alguns defendem bandeiras comuns que agreguem as lutas da juventude; outros reconhecem que isso é impossível, basta que os diferentes grupos conscientizem-se de porquê lutar. Há também discordâncias e antagonismos em relação à burocratização, à centralização e ao autoritarismo nas organizações partidárias e estudantis. Uma divisão clara ocorre entre aqueles que defendem uma partidarização do movimento estudantil e outros que a abominam. Dos 12 militantes em organizações estudantis que entrevistamos, apenas três não eram filiados a partidos e delimitaram sua militância à causa de "melhoria do ensino universitário”. Um deles afirmou: “O debate que é feito no Diretório Central dos Estudantes é um debate muito cansativo, às vezes fratricida, parece que um quer destruir o outro e não construir um movimento que busque mais direitos, mais ganhos para os estudantes” (R. - UFF).

Esses três jovens ressaltaram que sua não-adesão aos partidos foi um ato de resistência, na medida em que quase sempre os jovens militantes dos movimentos estudantis são cooptados pelas facilidades e vantagens que os partidos oferecem aos estudantes filiados. Essa resistência deixa-os mais aptos a construir uma representatividade que seja mais próxima dos estudantes e de suas causas e também menos vulnerável à lógica dos interesses partidários. Por outro lado, os que defendem a partidarização invocam a necessidade de construir-se pautas comuns, o que somente o engajamento partidário permite.

A construção de um “nós” por meio da filiação aos partidos ou às associações estudantis faz-se por meio da ação e também do delineamento de uma identidade do "nós" em contraposição ao “eles”. Parece haver uma tendência à minimização das diferenças intragrupos e ao aumento das diferenças intergrupos, favorecendo que os de fora sejam vistos sempre como mais corrompidos por uma maneira “antiga” de fazer política. Desse modo, as críticas a como se age e a como se faz política sempre cabe aos outros. Por exemplo, os jovens dos partidos mais à direita criticam o fato de que o movimento estudantil está completamente partidarizado, o que quer dizer que os partidos financiam os estudos dos estudantes filiados, pagam-lhes viagens para participar de congressos de estudantes, financiam festas e eventos para atrair filiados... Nesse sentido, criticam a maneira de fazer política dos partidos de esquerda, que cooptam os estudantes por meio das vantagens pessoais que podem oferecer. Por outro lado, os que estão nos partidos de esquerda criticam a maneira como os da direita sempre cooptaram deputados, comprando seus votos nos projetos de interesse do governo. A direita é vista como representante direta dos interesses da oligarquia nacional. Em geral, a autocrítica parece ser absorvida com dificuldade por medo de enfrentarem-se os aspectos indignos do fazer político no próprio grupo. No limite, busca-se preservar uma imagem idealizada do partido e dos que nele militam. Alguns conseguem expressar a franca decepção com o partido e as razões de mudança partidária. Nesse sentido, pôde-se perceber que a relação com a política, enquanto instituição, aparece sempre gerando conflitos, seja porque os ideais partidários não se refletem na práxis, seja porque o fazer político sofre limitações, seja porque a tomada de decisões não resulta de um debate mais amplo. Os depoimentos abaixo ilustram tais preocupações: "Então a gente corre o risco do aluno, do estudante, do jovem ficar perdido e de não querer saber mais de política, pega nojo de política... E quanto mais a política vai gerar nesse meio de corrupção, de toma-lá-dá-cá, de lama, menos a gente vai oxigenar isso, menos a gente vai mudar isso" (D. - DEM). "Então, neste congresso eu pude ver que dentro da política brasileira, eu pude ver que... eu desiludi[-me] um pouco disso. Eu vi que tem muita corrupção, tem muita gente que não quer nada. Nesse congresso deu 20000 pessoas; dessas, cinco ou seis mil estavam a fim [de participar], o resto não estava; dessas que estão a fim, quem realmente manda são 100. Então, quem pode realmente fazer alguma coisa são essas 100 e eu não sou uma dessas 100 . Então, isso dá um desânimo!” (D. - USU).

De qualquer modo, as críticas ao modo de agir político encobrem uma questão que os jovens hesitam em propor-se mais explicitamente: como 
construir outro agir político que não se torne também corrompido? Será que a política força todos, de algum modo, a fazer concessões que, em princípio, renegam? Tais questões apenas insinuadas não puderam ser averiguadas completamente, mas sugerem uma enorme preocupação dos jovens em relação à sua ação futura como militantes.

A adesão ao partido ou à organização estudantil, para os jovens engajados nas militâncias partidária e estudantil, conduz a uma outra visão de si, do futuro e dos outros. Por meio dela, abre-se outra fronteira de enlaçamento com o social dada pelo que eles chamam de "uma visão crítica da sociedade” ou de uma "conscientização", caracterizando uma crise positiva de reordenamento de valores. É como se tudo, de repente, pudesse ser iluminado pelo sentido da luta contra a opressão e as injustiças; enfim, o sentido político ilumina todas as outras vivências do jovem. Dessa forma, a política, não como instituição, mas como visão crítica da sociedade, seria o significante que batiza a ingresso do jovem em uma outra vida em que pode ver com outros olhos a si mesmo, sua própria família, os problemas que o circundam e as determinações a que está submetido.

Assim, a política é sentida como uma forma de vida e de compreensão das relações sociais. Situar suas ações no horizonte da política significa para esses jovens dar novo sentido às experiências cotidianas à luz de outros entendimentos, que ampliam o raio de determinação dos acontecimentos. O espaço do grupo e das discussões no partido e nas organizações constitui-se como a sustentação objetiva dessa construção coletiva: estar em grupo fazendo ou discutindo realiza objetivamente o esforço para "ser político", ainda que essa experiência esteja pontuada por traições, rachas e conflitos.

III.2. A militância dos jovens em movimentos sociais. A adesão às causas humanitárias: o trabalho social como reparação

O outro grupo de jovens entrevistados estava inserido no trabalho social e comunitário voluntário. O percurso dos jovens assim engajados apresentou-se bastante variado, em muitos casos confundindo-se até com o resgate da própria história pessoal. Por exemplo, alguns jovens pobres que trabalhavam em ONGs em prol de outros jovens desfavorecidos afirmaram que seu ingresso nessas organizações permitiu-lhes "sair da rua", "largar as drogas e o caminho errado” e optar por um caminho de realização e trabalho. Nesses casos, as causas pessoais vão ao encontro de e mesclam-se às causas sociais, na medida em que viram na sua própria mudança a possibilidade concreta de trabalhar em prol da mudança de outros jovens nas mesmas condições.

Em geral, há uma preocupação dos entrevistados a respeito da falta de oportunidades causada pelas desigualdades sociais, aspecto que os motiva a realizar o trabalho social. Essa motivação é sentida como um "ter que agir", ainda que muitos deles reconheçam que fazem o que seria a obrigação do governo fazer: "É, eu acho exatamente isso, que as pessoas, na [sua] maioria, preferem ignorar mesmo o que está acontecendo às vezes diante dos próprios olhos - entendeu? - e falar mesmo que quem tem que fazer isso é o governo e que não têm nada a ver com isso. Bom, de fato não é a minha obrigação estar aqui, mas eu acho que - sei lá! - se o governo não faz, eu não vou simplesmente ficar quieto, entendeu? Eu acho que o maior problema com os jovens de hoje é o fato de eles não lidarem com essa questão social, de eles simplesmente fingirem que não existe” (F. Vetor).

A educação é considerada o instrumento por excelência de transformação e de justiça social. Alguns comentam a emoção de poderem ver outros jovens transformando suas vidas por meio do trabalho que realizam. É o caso de muitos que trabalham em cursos pré-vestibulares ou cursos preparatórios comunitários para jovens pobres: "Eu estava, eu fiquei maravilhado [...] de olhar aquelas pessoas, a grande maioria delas trabalhou o dia inteiro e estavam lá, de 7 da noite às 10, estudando com a maior garra, o que eu nunca tinha visto assim nas escolas onde eu estudei [...]. Ninguém tinha pego com tanta garra uma oportunidade como aquelas pessoas que estavam ali. Aquilo me emocionou muito" (P. - Lumina).

Em uma outra variante, mas na mesma linha de pensamento, os jovens pobres que trabalham, por exemplo, em rádios comunitárias e na formação artística e musical de outros jovens enfatizam as possibilidades identificatórias do seu trabalho e de sua vida para aqueles jovens pobres que nasceram e vivem nas mesmas condições que as deles. "Ser exemplo" para um enorme contingente de jovens e crianças que não têm nada a não ser o caminho das drogas e mostrar-lhes por meio das suas próprias vidas que há outras opções de vida 
e de realização parece ser o ideal que enlaça esses jovens ao trabalho social. Dois jovens dizem: "Então eu via meus amigos passando sufoco, tendo que fazer besteira para arrumar dinheiro, às vezes a gente quer andar bonito e tal. Então o circo foi uma forma de reverter essa história. Eu falei: ‘eu não quero fazer o mesmo que muitas pessoas estão fazendo, eu quero seguir um caminho diferente' [...]. Então eu quero passar a mesma coisa para as crianças, [para] que elas possam perceber que têm muitas escolhas, uma ou duas, tem milhões de escolhas, e podem ser escolhas boas” (M. - Afro-Reggae). "[...] Então a rádio comunitária está ali pra isso, né, mano? Pra dar a voz aos excluídos, né, mano? Porque às vezes você tem uma comunidade que é excluída assim, não tem voz, não tem nada, não tem ninguém que acolhe, só pessoas que chegam ali pra sugar da própria comunidade. Então, a rádio comunitária, ela já é diferente disso, ela está ali pra poder dar voz à própria comunidade e interagir também junto com a comunidade ao seu próprio crescimento" (F. Rádio Mme. Satã).

Com algumas variações em termos do percurso que fizeram até o ingresso no trabalho comunitário e social, todos os entrevistados estão unidos à causa de transformação de um outro - principalmente o outro destituído social e economicamente nas atuais condições das grandes cidades brasileiras -, em um movimento subjetivo de retribuir o que ganharam e em um processo de objetivar uma "reparação" da dívida social brasileira.

Alguns percebem um sentido político do trabalho social, não por sua inserção na máquina partidária, mas pela luta emancipatória cujo fim seria, em última análise, a contribuição para que seus pares possam usufruir de condições de liberdade e de igualdade. Para outros, o sentido político é terminantemente recusado, por justamente não quererem ter a ver com partidos políticos ou com políticos, vistos como corruptos e manipuladores. Nesse sentido, o vínculo com os excluídos é direto, sem intermediações, as quais podem impedir, atrapalhar ou desviar a ação reparadora: “Acho que a gente considerar política só o que o Estado coloca ou só atuar em termos de partido [...] não é correto. E, na verdade, acho que esse é um instrumento que está muito limitado. Eu vejo como um instrumento muito limitado. [Os] Partidos políticos hoje em dia têm muita bri- ga interna, eu já tive muito acesso a esse tipo de coisa e vi que os resultados talvez não sejam os melhores. Então, hoje eu me vejo na oportunidade de trabalhar com outras coisas que gerem mais resultados” (M. - Consciência Cidadã). “[...] Eu acho que partido [não tem] nada a ver. Partido é só uma forma de você se aliar, de fazer alianças e conseguir votos. Eu vejo assim. Porque é muito difícil que as pessoas pensem [de maneira] igual em todas as coisas e dá tanto problema isso. O cara sai do partido, vai pro outro, fica sem partido, não sei o quê... Eu acho que não tinha que ter partido, não" (T. - Alma).

A relação com a política institucionalizada é quase sempre de suspeitas, na medida em que as disputas, os debates e as diferenças são considerados fatores que atrasam, quando não impedem a ação engajada. É importante assinalar que essa percepção dos jovens entrevistados aparece também em estudos realizados em outros países, em que se constata que muitos jovens recusam a institucionalização política de suas ações - por meio da vida partidária, por exemplo - por ela estar mais a serviço da máquina partidária do que da transformação social (MUXEL, 1994; BAUGNET, 1996; ION, 1996; ION \& RAVON, 1998; GAUTHIER, 2003; REGUILLO, 2003). Portanto, tais jovens preferem uma via direta de ação e de participação na sociedade, em que podem constatar, por eles mesmos, os efeitos do que fazem, sem intermediações.

Ainda que considerado como uma obrigação moral pela qual se sentem convocados a agir, o vínculo aos destituídos por meio do trabalho social e comunitário não é sentido como excessivo ou "viciante", como foi no caso dos jovens do grupo anteriormente discutido. Assim se expressa um jovem que trabalha em um curso preparatório para o vestibular para jovens pobres: “A respeito da minha doação pessoal, eu tento me doar o máximo que eu posso. É bem verdade que me doar totalmente nem sempre é possível, principalmente quando a vida na faculdade aperta um pouco, com provas, fica complicado se doar muito, mas sempre que possível eu tento participar das reuniões e tento articular as coisas. Acho que é isso. Cada um faz o que pode” (P.- Lumina).

A ação visa a produzir efeitos visíveis de transformação nos outros. Desse modo, o trabalho tem que se realizar no seu próprio ritmo e as mudanças acontecem por força do investimento conti- 
nuado e da convicção de que se pode fazer alguma coisa para mudar o estado de coisas ao redor. Alguns entrevistados explicam seu distanciamento de uma atividade político-partidária dizendo que essas agremiações acabam tornando-se um fim em si mesmas, uma "carreira”, em que o que se aprecia são os cargos, exacerbando as vaidades pessoais dos próprios jovens e atiçando o desejo de uns terem mais "poder sobre os outros". Ou, ainda, criticam as associações estudantis por elas serem partidarizadas e não tolerarem a nãopartidarização das lutas. Assim, a desconfiança em relação à atividade político-partidária dirige-se ao seu eventual desvirtuamento no sentido da afirmação pessoal e do descompromisso com a mudança social produzindo apenas a rolagem institucional do status quo.

A relutância a respeito da partidarização expressa, talvez, uma dificuldade encoberta de os jovens enfrentarem a dispersão e os conflitos decorrentes da pluralidade de interesses e de idéias. Ainda que possam ser procedentes as críticas em relação ao descomprometimento com a ação e com a transformação a que a luta pelo poder pode eventualmente conduzir, os entrevistados desse grupo parecem recusar, de todo, a vinculação partidária como uma forma de agir politicamente. Colocam em questão a distância que se estabelece entre a discussão e a ação dos que militam nos partidos políticos e a minimização dos efeitos de sua ação sobre a ordem social.

Ainda que seu vínculo ao coletivo faça-se de modo mais pontual, centrado sobre o trabalho em relação ao outro desfavorecido, esse grupo de jovens expressa claramente os conflitos a que estão sujeitos pela sua opção de militância por meio do trabalho social: em primeiro lugar, com a família que ou desaprova ou acha exagerada sua dedicação; em segundo lugar, em termos da própria vida pessoal quando, em algum momento, a satisfação pessoal tem que ser adiada. De qualquer modo, não parece haver para esse grupo um adiamento dos estudos ou do trabalho em prol da adesão à causa, como no grupo anteriormente discutido.

O que parece fundamental no enlaçamento desses jovens à sociedade mais ampla é o contínuo processo de construção de um coletivo em que as opiniões pessoais de cada um devem convergir para metas comuns. Em um desses movimentos, tivemos a oportunidade de estar presente em uma reunião em que discutiam como obter financiamento e como seriam as atividades do próximo curso preparatório que estavam planejando. A reunião durou cerca de seis horas, porque todos achavam que as diferenças de opinião tinham que ser expressas e somente quando todos concordassem em relação aos pontos discutidos a discussão deveria acabar. Nesse sentido, parece enorme o investimento psíquico que esses jovens fazem na direção da construção de seu vínculo com o grupo social mais amplo, encarado e vivido na lenta superação das diferenças, apostando que um trabalho comum possa ser abraçado por todos, nem que para isso tenha que haver um esforço incomum alimentado pelo ideal da construção coletiva.

\section{III.3. Participação: da "política” “ ao "políti-} co"?

A apresentação dos resultados permite-nos fazer algumas considerações sobre os aspectos comuns e comentar as divergências entre os dois grupos de entrevistados. Destaca-se, em ambos os grupos, a busca de um vínculo com o social que dê outros sentidos às suas relações com o mundo e insira o jovem em um coletivo de ação na sociedade.

Pari passu à construção de um novo lugar, reconstroem-se também as ligações com a família e as expectativas desta em relação ao jovem. Não é à toa que todos os jovens, independentemente do grupo a que estão filiados, enfrentem conflitos com os pais e redirecionem escolhas profissionais. A busca de uma nova inserção conduz à luta que também se trava internamente, consigo mesmo, do que advirá uma nova compreensão de si, de sua inserção no mundo e da convivência social.

No entanto, muitos afirmam que foi justamente da família que vieram suas primeiras percepções sobre temas políticos, seja por meio de discussões, seja por meio do exemplo dos pais. Mas também dos professores, principalmente de História e de Geografia, citados como aqueles que mais incentivam a "ver a realidade de outra forma”, a "questionar", a "ser mais crítico".

O tema da democracia revela-se pleno de reticências e ambigüidades nas falas de todos os jovens: a maioria diz crer na democracia como melhor forma de governo, mas não acha que o que se esteja vivendo no Brasil possa se chamar de democracia, seja porque não há justiça social, seja 
porque a representatividade é uma fraude, seja porque o governo é opressor, seja porque não há participação real da sociedade. Dessa forma, os jovens de ambos os grupos e de todos os espectros ideológicos, convergem para uma crítica explícita à maneira como suas vidas são governadas por um poder que não lhes diz respeito e que dissimula seus aspectos autocráticos. Assim, fazem eco à afirmação do historiador José Murilo de Carvalho (2002, p. 278): “No Brasil, a política é apenas formalmente democrática”.

A crítica ao fazer político vigente também encontra ressonância em ambos os grupos, que reclamam da corrupção na política, mas diferentes propostas de ação são encaminhadas. O grupo de jovens ligado ao trabalho social e comunitário parece ver na adesão partidária - dos grupos partidários juvenis ou dos movimentos estudantis uma solução continuísta e também corruptível, que não rompe com as mazelas de irresponsabilidade e descompromisso do fazer político. Nesse sentido, tentam encaminhar uma ação cujo compromisso com a realidade social seja preservado "na sua essência”, afastando-se das causas partidárias que lhes parecem sectárias e pouco abertas à pluralidade de idéias. O compromisso com a causa humanitária assume, algumas vezes, uma interface com os movimentos culturais e expressivos dos jovens ligados à crítica social, como o rap e o hip hop. Assim, o vínculo dos jovens aos outros destituídos busca investir em uma participação efetiva de transformação da sociedade, iluminada por uma imagem holística e utópica do todo social.

Seus pares que militam nos partidos e nos movimentos estudantis também tecem críticas ao fazer político, cujo desvirtuamento é atribuído, sobretudo, aos outros partidos, não propiciando, assim, atitudes de autocrítica. No entanto, há que se reconhecer que o ingresso dos jovens nas organizações partidárias expõem-nos inexoravelmente à violenta pluralidade de interesses que os partidos políticos incorporam e às soluções e encaminhamentos no âmbito dos partidos, que nem sempre contemplam a pureza dos princípios ideológicos, mas o pragmatismo das decisões. O horizonte do político acaba circunscrevendo-se à luta encarniçada pelo poder, perdendo sua qualidade de arena que encerra a pluralidade e o enfrentamento do adversário, na maioria das vezes apenas considerado como o inimigo a ser vencido ou destruído.
Por um lado, os jovens militantes do trabalho social e comunitário apostam na preservação de um ethos de transformação de mundo em que todos possam estar consensualmente integrados e harmonizados; por outro lado, os jovens militantes de partidos ou de agremiações estudantis lançam-se à defesa da ação partidária programática e têm que encarar a luta aberta e adversa de diversos grupos de interesse marcados por métodos nem sempre legítimos. Em ambos os grupos, ainda que por caminhos e inserções diferentes, percebe-se o desejo de transformação de um mundo desigual e injusto.

Assim, os jovens põem em evidência a difícil conquista de um espaço organizado por meio do qual possam fazer valer suas expectativas de mudança social. Se nos dois grupos de entrevistados é patente seu inconformismo perante o status quo e a busca de construção de um coletivo pelo qual as mudanças podem ser operadas, tanto pela via partidária como pela do trabalho voluntário engajado, há dificuldades no estabelecimento de uma conjunção da política com o político. A “política” é entendida como o modus operandi socialmente legitimado e organizado de levar adiante mudanças societárias no horizonte de lutas e antagonismos; o "político" é visto como construção coletiva contra-hegemônica que visa a restabelecer o vínculo com os excluídos. Para os jovens aqui entrevistados, ao levantar-se a bandeira $d a$ política corre-se o risco de tornar-se parte de uma engrenagem em que se pode perder de vista o compromisso com a mudança real e com os princípios partidários. Ou, ao preferir-se $o$ político, engajando-se no trabalho voluntário engajado, corre-se o risco de se evitar confrontar e lidar com as engrenagens mais amplas a que estão submetidos e os diversos interesses que dividem a sociedade mais ampla.

\section{CONSIDERAÇÕES FINAIS}

A “causa comum” traduz a passagem dos jovens a um outro lugar na sociedade fora da família de origem, inserindo-os nas relações sociais mais amplas. Ela denota a resposta dos jovens frente ao mal-estar que experimentam ao depararemse com injustiças e desigualdades sociais, interpelando-os à responsabilidade por tal situação. As respostas dos jovens, como vimos, não são isentas de conflitos e impasses. O que parece importante assinalar é que elas põem em curso diferentes modalidades de ação, todas aspirantes a trans- 
formar a sociedade em direção a mais justiça, liberdade e igualdade.

Os jovens engajados no trabalho social engajado visam a não perder de vista a "causa" dos destituídos ao longo da organização e da efetivação da ação. Seu afastamento das instituições políticas, como os partidos, revela decepção com os interesses "vindos de cima" que solapam o comprometimento com a transformação social. Nesse sentido, preferem permanecer circunscritos à ação local, de modo a constatar "com seus próprios olhos" qual a eficácia que tal ação possui. Os que se engajam em partidos e nos movimentos estudantis pensam que somente dentro dessas organizações será possível transformar radicalmente a sociedade no âmbito de um projeto de nação. No entanto, esses jovens vivem os conflitos em relação às concessões que a luta partidária parece demandar, uma vez que a ação política está submetida a um enquadramento de interesses mais amplos. Em ambos os casos, o cenário de desigualdades sociais parece ser o aspecto que convoca à ação, incitando a transformação do estado de coisas ao redor.

A corrupção do fazer político nas instituições formais é duramente criticado. Pelos jovens que estão militando nos partidos, essa crítica acompanha-se de angústias e questionamentos em relação à sua futura trajetória: de que modo os objetivos partidários podem vir a legitimar os meios? Até onde compromissos podem ser feitos? Além disso, muitos deles mostraram claramente sua decepção e suas frustrações com o jogo político e professam atitudes "realistas" quando confessam que estão convencidos de que "a política tem limitações”. Ou seja, as mudanças, ainda que acalentadas, nem sempre são alcançadas. Para aqueles que ingressaram e permanecem no trabalho social engajado, essas dúvidas parecem ter sido respondidas ao optar-se pela distância em relação aos mecanismos formais de participação política. Parece ser uma resposta de esquiva ao enfrentamento das lutas de interesses mais amplos que podem incidir sobre a ação engajada. Ainda assim, é importante notar o questionamento que fazem das formas convencionais de luta pela igualdade e pela emancipação e sua opção pela militância por meio do trabalho social voluntário, o que abre espaço para que se discutam outras maneiras de combater-se a opressão. Nessa linha de pensamento, Terry Eagleton afirma que é justamente do ponto de vista subalterno e pontual que a sociedade pode enriquecer-se e reinventar modos de embate contra as injustiças: "A sociedade não pode ser totalizada de um ponto de vista privilegiado acima dela mesma, mas de um ponto subordinado dentro dela. A lógica de uma situação geral só pode ser decifrada pelos que a olham de um ângulo específico, já que são eles que mais necessitam desse conhecimento para o fim de sua emancipação. Eles estão, a bem dizer, na posição de saber, uma expressão simples que nega que a 'posicionalidade' seja necessariamente contrária à verdade" (EAGLETON, 2000, p. 81; sem grifos no original).

Assim posicionados nas bordas dos mecanismos estabelecidos de pressão e reivindicação, os jovens questionam as visões de Brasil e as formas de convivência que o fazer político tem reproduzido ao longo da república brasileira.

Concluindo, cabe perguntar sobre os delineamentos futuros das formas de participação política que os jovens têm encaminhado. Cabe questionar se as críticas ao fazer político, tanto por parte dos que militam nos partidos, como dos que se engajam no trabalho social e comunitário, trarão um renascimento das instituições políticas ou se permanecerão anódinas às engrenagens partidárias legitimadas. Será que a participação política dos jovens, sob suas várias formas e ainda como surplus e energia pouco organizada, contribuirá para trazer para mais próximo o ideal da democracia no Brasil? As ações dos jovens aqui pesquisados venceram a apatia e o conformismo, juntando-se à causa da transformação social e instituindo formas de lidar com o mal-estar da convivência. Nesse sentido, suas ações acompanham um processo crescente de politização da vida social, como afirma Ernesto Laclau (1994, p. 4): “[...] nas sociedades pós-modernas há tanto o declínio dos grandes atores históricos quanto dos espaços públicos centrais, em que as decisões importantes para a sociedade como um todo eram tomadas. Mas, ao mesmo tempo, há uma politização de vastas áreas da vida social que abre caminho para uma proliferação de identidades políticas particulares”. Nesse sentido, parece ser tanto no limite quanto no exterior das atividades convencionalmente tidas como políticas que a política adquire algum sentido e importância para muitos jovens no Brasil hoje, justapondo ideais de transformação do presente com os de reparação social, ambos podendo ser concebidos como reordenações do vínculo com o social e permitindo ao jovem o compromisso com o destino comum. 
Lúcia Rabello de Castro (lrcastro@infolink.com.br) é Doutora em Psicologia pela Universidade de Londres e Professora Titular do Departamento de Psicologia Clínica da Universidade Federal do Rio de Janeiro (UFRJ)

\section{REFERÊNCIAS BIBLIOGRÁFICAS}

ABRAMO, H. \& BRANCO, P. 2005. (orgs.) Retratos da juventude brasileira : análises de uma pesquisa nacional. São Paulo : Fundação Perseu Abramo.

ARENDT, H. 1963. On Revolution. New York : Penguin.

1972. Entre o passado e o futuro. São Paulo : Perspectiva.

BAUGNET, L. 1996. Participation associative et rapport au politique : l'engagement social des jeunes. In : ROUDET, B. (org.). Des jeunes et des associations. Paris : Harmattan.

BECK, U. 1998. Le conflit des deux modernités et la question de la disparition des solidarities. Lien Social et Politiques, Montreal, n. 39, p. 15-25.

CARVALHO, J. M. 2002. Pontos e bordados. Belo Horizonte : UFMG.

CELLIER, H. 2004. Citoyenneté, école et projets fédérateurs : novelle cohérence sociale ? In : VULBEAU, A. (org.). La jeunesse comme ressource. Paris : Ères.

DOMINGUES, J. M. 2000. A cidade : racionalização e liberdade em Max Weber. In : SOUZA, J. (org.). A Atualidade de Max Weber. Brasília: UNB.

EAGLETON, T. 2000. The Idea of Culture. London : Sage.

FLANAGAN, C. \& SHERROD, L. 1998. Youth Political Development : An Introduction. Journal of Social Issues, v. 54, n. 3, p. 447456.

FORBRIG, J. 2005. Introduction : Democratic Politics, Legitimacy and Youth Participation. In : . (ed.). Revisiting Youth Political Participation. Strasbourg: Council of Europe.

GAUTHIER, M. \& GRAVEL, P. 2003. La participation des jeunes à l'espace public au Québec, de l'associationnisme à la mobilisation. In : GAUTHIER, M. (org.). La jeunesse au
Québec. Montreal : Université Laval.

GRIFFIN, C. 2005. Challenging Assumptions about Youth Political Participation : Critical Insights from Great Britain. In : FORBRIG, J. (ed.). Revisiting Youth Political Participation. Strasbourg : Council of Europe.

IBGE. 2003. Síntese dos indicadores sociais de 2002. Rio de Janeiro : Instituto Brasileiro de Geografia e Estatística.

INGLEHART, R. 1997. Modernization and Postmodernization. Cultural, Economic and Political Change in 43 Societies. Princeton : Princeton University.

ION, J. 1996. Groupements associatifs et modèles d'engagement. In : ROUDET, B. (org.). Des jeunes et des associations. Paris : Harmattan.

ION, J. \& RAVON, B. 1998. Causes publiques, affranchissement des appartenances et engagement personnel. Lien Social et Politiques, Montreal, n. 39, p. 59-71.

KOVACHEVA, S. 2005. Will Youth Rejuvenate The Patterns of Political Participation? In : FORBRIG, J. (ed.). Revisiting Youth Political Participation. Strasbourg : Council of Europe.

LACLAU, E. 1994. Introduction. In : (ed.). The Making of Political Identities. London : Verso.

LEFEBVRE, H. 1974. La production de l'espace. Paris : Anthropos.

MOUFFE, C. 1993. The Return of the Political. London : Verso.

MUXEL, A. 1994. La formation des choix politiques dans le temps de la jeunesse. Filiation et expérimentation. In : L'Identité politique. Paris : PUF.

NEGT, O. 2002. Espaço público e experiência. In : PALLAMIN, V. (org.). Cidade e cultura : esfera pública e transformação urbana. São Paulo : Estação Liberdade. 
PLEYERS, G. 2005. Young People and AlterGlobalisation : From Disillusionment to a New Culture of Political Participation. In : FORBRIG, J. (ed.). Revisiting Youth Political Participation. Strasbourg : Council of Europe.

POLIS-IBASE. 2006. Diálogo nacional para uma política pública de juventude. São Paulo : Instituto Pólis-Instituto Brasileiro de Análises Sociais e Econômicas. Disponível em : http:// w w w. i b a s e. b r / u s e ri m a g e s/ dialogo_juv_final21.pdf. Acesso em : 15.mar.2008.

RANCIÈRE, J. 1995. Politics, Identification and Subjectivization. In : RAJCHMAN, J. (ed.). The Identity in Question. London : Routledge.

REGUILLO, R. 2003. Cascadas : agotamiento estructural y crisis del relato. Pensando la "participación” juvenil. In : ISLAS, J. A. P.; GONZALEZ, M. V.; GAUTHIER, M. \& GRAVEL, P. L. (coords.). Nuevas miradas sobre los jóvenes. México y Québec. Ciudad de México : Instituto Mexicano de la Juventud.
SANTOS, M. \& SILVEIRA, M. L. 2001. O Brasil : território e sociedade no início do século XXI. São Paulo : Record.

SENNETT, R. 1992. The Fall of the Public Man. New York : Norton.

STOLLE, D. \& HOOGHE, M. 2004. Inaccurate, Exceptional, One-Sided or Irrelevant? The Debate about the Alleged Decline of Social Capital and Civic Engagement in Western Societies. British Journal of Political Science, Cambridge, UK, n. 35, p. 149-167. Disponível em : http://www.kuleuven.be/citizenship/ _data/reviewarticle.pdf. Acesso em : 15.mar.2008.

VILLA, D. (1992). Postmodernism and the Public Sphere. American Political Science Review, Washington, D. C., v. 86, n. 3, p. 712-721.

WELTI, C. 2002. Adolescents in Latin America : Facing the Future with Skepticism. In : BROWN, B.; LARSON, R. \& SARASWATHI, T. (eds.). The World's Youth : Adolescence in Eight Regions of the Globe. Cambridge : Cambridge University.

Artigo modificado por solicitação do editor em (Abril/2009). 